The text begins presenting the arisen of he philosophical-poetic comics in Brazil. Next it shows de different expressions which have been used to define the type, at the same time that it sets the discussion about the construction of its identity. From the contribuition of artists, scholars and researchers it bulids a definition of philosophical-poetic comics and it tries to identify its main features. In conclusion it suggests that philosophical-poetic comics can participate in the art-communication-education dialogue in the buliding process of answers to the problems experienced by the contemporary society.

Keywords: philosophical-poetic comics, Revista Mandala, Revista Tyli-Tyli. 


\section{O que são histórias em quadrinhos poético- filosóficas? Um olhar brasileiro}

Elydio dos Santos

NETO

O texto inicia apresentando o surgimento dos quadrinhos poético-filosóficos no Brasil. Em seguida mostra as diferentes expressões que têm sido utilizadas para definir o gênero, ao mesmo tempo em que explicita a discussão em torno da construção de sua identidade. A partir das contribuições de artistas, estudiosos e pesquisadores constrói uma definição de quadrinhos poético-filosóficos e procura identificar suas características principais. Conclui sugerindo que as histórias em quadrinhos poético-filosóficas podem participar, no diálogo arte-comunicação-educação, dos processos de construção de respostas aos problemas vivenciados na sociedade contemporânea.

Palavras-chave: Quadrinhos poético-filosóficos, Revista Mandala, Revista Tyli-Tyli. 


\section{Um convite à leitura...}

Convido o leitor ou leitora deste artigo a fazer uma pequena "transgressão" e iniciar a leitura deste trabalho pela história em quadrinhos, intitulada "Parto", de autoria de Edgar Franco, publicada no ensaio visual deste número da Visualidades. Ao terminar de ler procure responder a si mesmo/mesma a seguinte pergunta: Esta história que acabo de ler é, de fato, uma história em quadrinhos? Mas onde estão os tão famosos baIões? E os diversos e diferentes requadros que existem em uma página? É possível que em uma HQ possam existir páginas com um único requadro que se identifica com a própria página? E quanto à temática? Há público para uma temática de reflexão tão séria, envolvendo aspectos filosóficos e éticos da existência humana, numa linguagem que é considerada quase sempre como de entretenimento? Não é uma HQ muito curta para o tamanho do problema que se propõe a refletir?

Assim como Edgar Franco outros artistas têm criado HQs com estas mesmas características e tais histórias vêm sendo definidas de forma diferente pelos vários autores que sobre ela se debruçam: HQs poéticas, HQs filosóficas, HQs de fantasia filosófica ou HQs poético-filosóficas.

O objetivo deste trabalho é examinar a origem deste gênero de HQs no Brasil, definir suas características principais e apontar para as implicações de sua produção nos limites das artes, da comunicação e da educação. Optei, mesmo correndo certos riscos, em transcrever citações, ainda que longas, sempre que julguei importante registrar um depoimento ou então fragmentos de artigos que foram publicados em revistas de histórias em quadrinhos e outros materiais bibliográficos que não são de fácil acesso. Compreendo que esta é uma maneira de recolher de forma mais sistematizada um rico material que se encontra atualmente disperso.

\section{Quando e com quem surgiram os quadrinhos poético-filosóficos no Brasil}


Desde o final da década de 1980 um grupo de artistas no Brasil vem elaborando uma produção no campo dos quadrinhos chamada por alguns de "quadrinhos poéticos", por outros de "quadrinhos poético-filosóficos" e, por outros ainda de "fantasia filosófica" ou "quadrinhos fantástico-filosóficos". São representantes conhecidos e significativos deste grupo de artistas: Flávio Calazans, Edgar Franco, Gazy Andraus, Henry e Maria Jaepelt, Wally Viana, Joacy Jamys, Luciano Irrthum, Eduardo Manzano e Antonio Amaral.

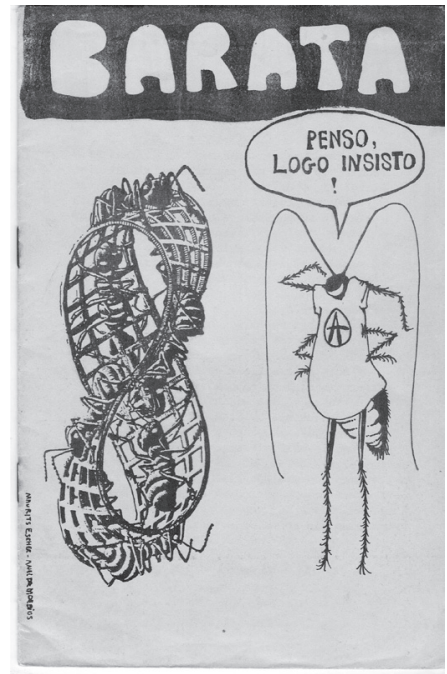

Figura 1 - Capado Barata 8

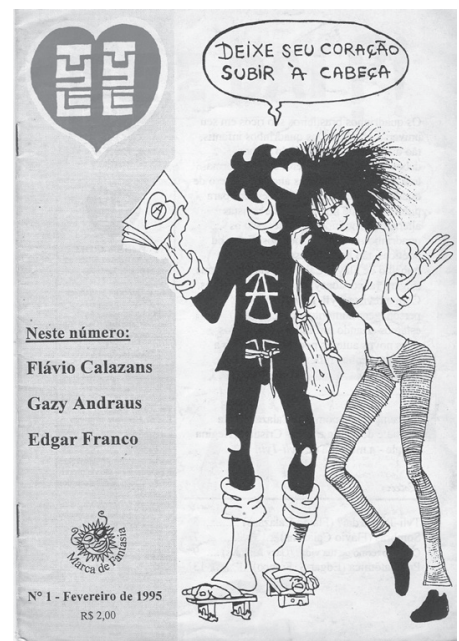

Figura 2 - Capa Tyli-Tyli 1

De acordo com Franco (1997) Calazans pode ser considerado como um dos precursores no Brasil deste quadrinho de fundo filosófico. Foi por muitos anos editor do fanzine Barata e está na origem de produções editoriais que abriram espaço para os quadrinhos filosóficos. O fanzine Barata (figura 1) e a revista Tyli-Tyli (figura 2) são dois exemplos expressivos. No Barata possibilitou que autores como Gazy Andraus (figura 3) 


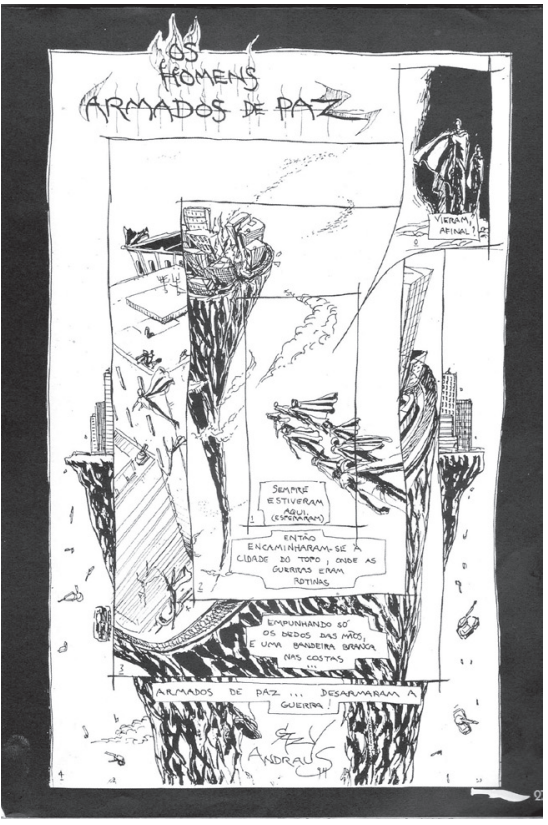

Figura 3 - HomensArmPaz-Gazy Andraus

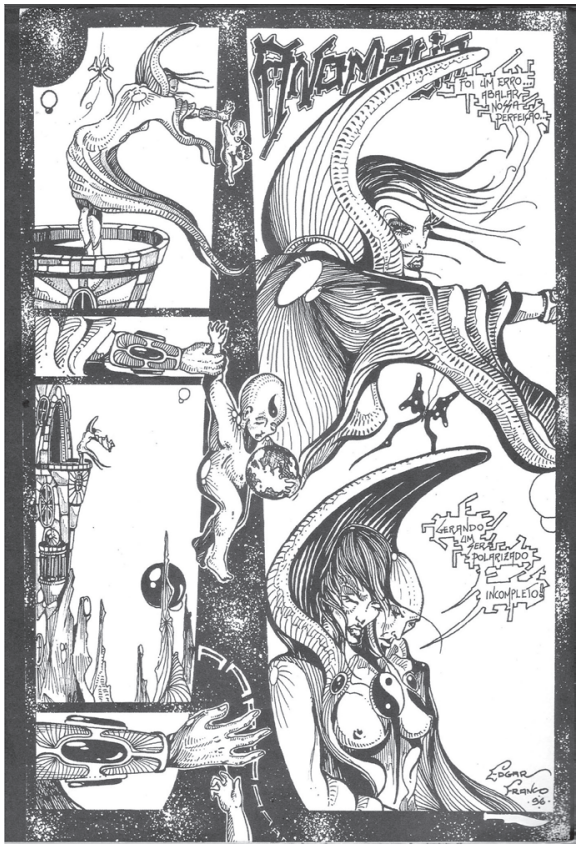

Figura 4 - Anomalia-Edgar Franco

e Edgar Franco (figura 4) pudessem não apenas mostrar sua produção, mas também se conhecer e construir novos caminhos no campo dos fanzines e dos quadrinhos. Em depoimento a mim concedido, Gazy Andraus revela que conheceu Flávio Calazans entre o final de 1986 e início de 1987, e que este encontro foi importante para sua constituição como desenhista de tendência poético-filosófica. Nas palavras do próprio Andraus (2007a, p. 2):

Desenhei bastante também em Goiânia, durante um ano e meio, período em que fiquei lá, mas quase não fazia histórias em quadrinhos, tendo voltado depois ao Estado de São Paulo, reiniciando o curso de Artes na FAAP. Pouco antes disso, no final de 1986 para o início de 1987, retomei os quadrinhos. Aconteceu dessa forma: eu estava desestimulado com o curso (em Goiânia) porque havia muita greve, e também estava meio sem vontade de fazer 
HQs com super-heróis. Então, num dos retornos a São Vicente (cidade onde resido), conheci o Flávio Calazans num sebo de Santos. Ele se apresentou e me convidou para participar do fanzine "Barata" que editava em cooperativa com seus amigos do curso de publicidade da UNISANTOS. As HQs do Barata eram bem diferentes do mainstream.

Foi com esse estímulo que reiniciei a fazer histórias em quadrinhos, e logo na terceira HQ que fiz, meu estilo que misturava poesia e espiritualidade numa estética diferente, já principiou a aparecer.

Ao lado da história de sua produção pessoal, que tomou novos rumos e ampliou-se a partir de suas publicações no Barata em 1987, Gazy Andraus (2008c), em seu conjunto de textos sobre sua memória de vida sob o enfoque visual, relembra como foi seu encontro com Edgar Franco por meio do mesmo fanzine editado por Calazans:

Em 1992, logo após o término de minha faculdade, minha mãe falecera de ataque cardíaco, corroborado pelo exagero do fumo de cigarros.

Pouco depois desse período, um fato curioso se deu: encontrei uma HQ no número 17 do "Barata", muito similar a meu estilo. Ela se chamava "Progéria Interior" e era assinada por alguém que eu não conhecia: Edgar Franco. Qual não foi minha surpresa ao me deparar com o endereço do autor: ele indicava a cidade de Ituiutaba, em Minas Gerais, a mesma que eu nasci.

Quando escrevi para ele, descobri que morava em Brasília cursando arquitetura na UNB, mas nas férias sempre voltava à sua cidade natal, coincidentemente, a minha. Pois marcamos de nos conhecer numa das férias, o que acabou por angariar uma sólida amizade, em que nos tratamos até como "irmãos". Edgar, apesar de ser 5 anos mais novo que eu, e nunca ter visto meu trabalho antes, elaborava HQs similares a mim, de conteúdo complexo, filosófico, mas de número de páginas reduzido. Nosso estilo acabou, depois, sendo reconhecido por Fantasia Filosófica.

Isto se deu da seguinte forma: resolvemos criar um fanzine único em dupla, chamado "Irmãos Siameses". Fizemos o lançamento, inclusive, no mês de junho de 1994 na Gibiteca de Santos. Tiramos umas 50 cópias xerocadas do zine, e depois dividimos o que restou, após o lançamento.

Ele continha várias histórias nossas: a primeira era dele, e a última minha, sendo que as do miolo se alternavam em roteiros meus com desenhos dele e vice-versa. A coincidência é que tanto 
a primeira como a última HQs tinham um enfoque temático e estrutural muito similar: é como se cada um de nós, sem termos conhecimento prévio, tivéssemos realizado uma HQ igual, cada qual com seu estilo! Isto me chamou tanto a atenção que lhe disse que ambas as histórias tinham que iniciar e finalizar o fanzine.

Depois, mandamos uma cópia para o evento realizado anualmente em Ourense, na Espanha galega. Lá, seu organizador, Henrique Torreiro nomeou nosso trabaIho de "fantasia filosófica autêntica", de onde acabamos por utilizar tal nomenclatura como o estilo por nós realizado: roteiros curtos, condensados como hai-kais, e arte vanguardista ${ }^{1}$.

Calazans é, pois, um nome importante para a constituição do gênero poético-filosófico no Brasil, seja por seu trabalho como editor no fanzine Barata ou pelas HQs filosóficas que ele próprio escreveu e desenhou (figura 5). Henrique Magalhães (2004, p. 46-49) confirma esta afirmação em texto de sua autoria sobre os vários grupos que publicavam fanzi-

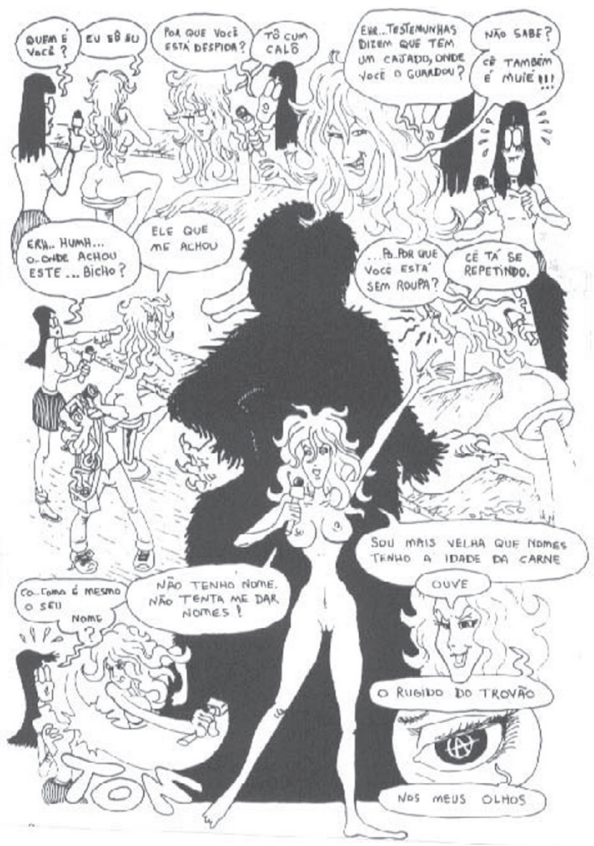

Figura 5 - Calazans nes entre as décadas de 1980 e 1990:

Desses grupos, um que muito se sobressaiu foi a Cooperativa Barata, capitaneada por Flávio Calazans, editor da revista Barata. Com coerência e sempre reunindo um bom time de participantes, a Barata - que, lembramos está mais para uma revista independente que para um fanzine - manteve-se firme em sua proposta durante quase todo o percurso.

Apenas no final da década de 1990 os membros da Cooperativa Barata deram sinal de saturação e perderam um pouco do prumo. (...) Enfim, o grupo encerrou suas atividades com o número 26 da revista Barata, de outubro de 2000, após 21 anos de produção. Apesar desse desfecho melancólico, a experiência da 
Cooperativa Barata pode servir de exemplo a outros grupos que desejem fazer um trabalho dentro do espírito coletivo e bem mais estruturado. (...) Com espírito crítico e irrequieto, por vezes polêmico, Calazans notabilizou-se, também, pela edição de álbuns. No início dos anos 1990, lançou com Paula Prata, Absurdos: quadrinhos sob hipnose, uma obra que marcaria seu processo espontâneo de criação. Calazans radicalizou na concepcão da obra. realizando-a sob hipnose. (...) Outro trabalho não

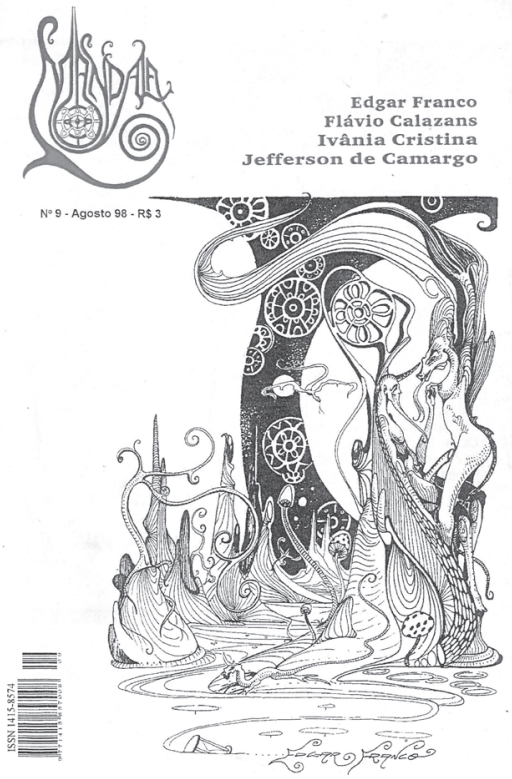

Figura 6 - Mandala menos significativo foi o álbum Guerra das Idias. Nesta obra já clássica da produção independente brasileira, temos um verdadeiro tratado libertário que conta de forma sintética e provocadora a história das lutas da humanidade, confrontando as idéias revolucionárias aos sistemas estabelecidos. Ainda, dentro da produção calazanista - como ele mesmo denominou sua obra -, temos A Hora da Horta, um libreto que reconta os primórdios da história do Brasil, por ocasião das comemorações dos 500 anos do descobrimento.

As HQs poético-filosóficas, por seu caráter autoral e não-comercial, encontraram seu espaço mais adequado de publicação nos fanzines, editados e publicados pelos próprios autores, mas chegaram a ter também revistas independentes. É o caso da revista Tyli-Tyli que posteriormente, a partir do número 9, passou a chamar-se Mandala (figura 6). Ambas foram publicadas pela Editora Marca de Fantasia, tendo como editor Henrique Magalhães 3 (2004, p. 57-58), que explica porque aconteceu a mudança da revista:

A revista Tyli-Tyli congregou toda uma nova geração de quadrinhistas, que inspirados nos "quadrinhos poéticos" passaram a produzir suas histórias de forma muito pessoal e experimentando uma estética diferenciada dos quadrinhos convencionais.

Com o afluxo de novos autores e diversidade de expressão, a revista deslocou-se de sua inspiração original vinculada à obra 
de Calazans e mudou de nome para Mandala, tornando-se mais abrangente. Esta revista trouxe uma auto-reflexão sobre o conceito de "quadrinhos poéticos", procurando definir suas diretrizes.

O caráter não popular dos trabalhos poético-filosóficos, a exigir também um leitor diferenciado, criou dificuldades para a continuidade da revista Mandala, como explica Henrique Magalhães em entrevista a mim concedida (2007):

Com o tempo os quadrinhos poéticos passaram a ser muito herméticos, a representar uma viagem muito interiorizada dos autores. Ao mesmo tempo, vinham embasados cada vez mais numa bibliografia centrada nas novas tecnologias. Alguns quadrinhos, para serem entendidos, tinham que trazer um texto explicativo sobre cada referência. Isto complicou demais e até tirou a força comunicativa da linguagem dos quadrinhos, que é contar uma história em seqüência. Os leitores se afastaram ou perderam interesse pelo gênero, restando um círculo de alguns autores-leitores.

Apesar de minha insistência em continuar produzindo a revista, a procura foi diminuindo na medida em que aumentava o número de autores-colaboradores, o que me levou a crer que a publicação não estava saindo de seu restrito círculo. A última edição, número 13, não teve compradores, o que fez perder o sentido a continuidade de sua produção.

Outro fator foi a falta de periodicidade. Como a Mandala era uma produção independente, voltada para o meio dos leitores de fanzines, a distância de uma edição a outra fez com que os leitores perdesse o interesse pela publicação. Creio que isto ocorre com todas as publicações seriadas no meio independente. Preferi partir para a edição de livros e álbuns, que são trabaIhos fechados em uma edição e não dependem de periodicidade.

Além das revistas Tyli-Tyli e Mandala a Editora Marca de Fantasia publicou também álbuns contendo especialmente trabalhos poéticos ou filosóficos: Guerra das Idias, de Flávio Calazans, foi publicado em 1997 e em 2001; Ternrio M.E.N., de Gazy Andraus, em 2001; Agartha, de Edgar Franco, em 2002; Guerra dos Golfinhos, de Calazans, em 2002; Transessncia: transcendendo a essncia, de Edgar Franco, em 2003 e Elegia, também de Edgar Franco, em 2005. Acompanha Elegia um CD com a leitura musical da HQ criada por Edgar Franco, 
sendo as composições de autoria de Grim e Naberius, músicos da Banda de Black Metal Sinfônico "Eternal Sacrifice".

É importante lembrar que além destes artistas acima destacados há outros, menos conhecidos talvez, mas também com produção no gênero e que tiveram espaço para apresentação de seus trabalhos junto às publicações da Editora Marca de Fantasia. Entre outros, podem ser citados Érika Saheki, Ivânia Cristina, Jefferson Camargo, Al Greco, Rosemário, Michel, Nuno Nisa Reis, Rafael Lopes, Manoel Macedo, Norival Bottos Júnior, Lavoisier, Caique, Whisner, Soter Bentes, André Marron Gavazza, Flávio Rafael, Fabio Mor, Murilo Rufião e André Marron.

A Comix Book Shop publicou, em 1996, a Brasilian Heavy Metal e nela tiveram espaço para publicação alguns autores

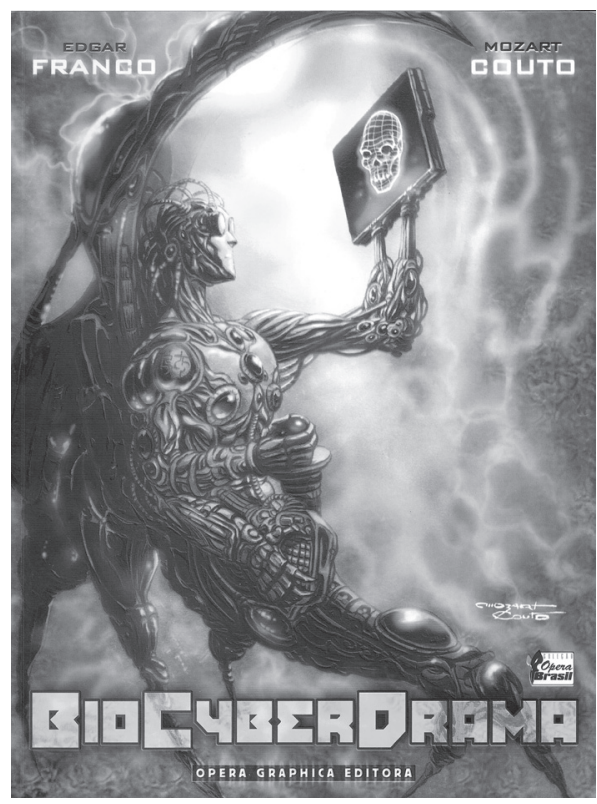

Figura 7 - biocyberdrama de quadrinhos poético-filosóficos: Antônio Amaral, Flávio Calazans, Gazy Andraus, Edgar Franco e Luciano Irrthum.

Wellington Srbek publicou em 2001, com a Lei de Incentivo à Cultura da Prefeitura de Belo Horizonte, o álbum Quantum, com texto de sua autoria e desenhos de Fernando Cypriano, Leonardo Muniz e Luciano Irrthum. O trabaIho, de modo especial pela temática reflexiva e filosófica, e também pela narrativa curta e criativa (embora mais longa do que aquilo que habitualmente se vê no gênero), pode ser considerado como sendo do gênero poético-filosófico.

A Opera Graphica Editora publicou no ano de 2003, com texto de Edgar Franco e arte de Mozart Couto, o álbum BioCyberDrama (figura 7), na coleção Opera Brasil, no qual Franco, como roteirista, apresenta com maiores detalhes, inclusive em texto introdutório à $\mathrm{HQ}$, seu universo ficcional da aurora pós-humana. A mesma editora, em 
parceria com Edições Pulsar, publicou também Hipocampo: $3^{a}$. Ocorrncia (s/d), de Francisco Amaral (figura 8).

Também Edgard Guimarães ${ }^{4}$ deu uma contribuição importante para a divulgação do novo gênero no campo dos quadrinhos, de acordo com o relato de Andraus $^{5}$, que publicou com ele o seu importante trabalho Homo Eternus $(1993 a, b, c, d)$ :

Porém, antes mesmo de conhecer o trabalho de quadrinhistas que faziam HQs similares, como Edgar Franco, eu fui motivado por Calazans a produzir uma auto-edição, para ser co-editada e publicada pelo Edgard Guimarães, (não confundir com Edgar Franco, e nem com Henrique Magalhães) em seu, então IQI - Informativo de Quadrinhos Independentes.(...) Este "Homo Eternus", como uma quadrilogia, tinha também uma capa especial para a edição encadernada, caso o leitor preferisse depois, em lugar de adquirir os vo-

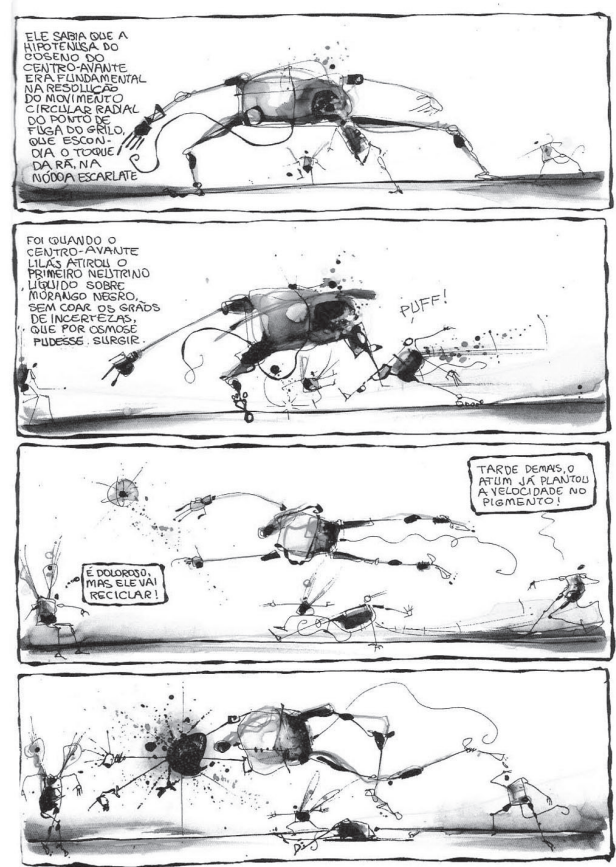

Figura 8 - Hipocampo lumes em separado. O IQI trazia divulgado um volume a cada bimestre e o encadernado após a divulgação dos 4 volumes. Para o prefácio convidei Guimarães e Calazans, e fechando cada volume, inseri dois textos meus que sintetizavam os objetivos do "Homo Eternus". A receptividade foi boa, pois aos poucos os leitores amantes de HQs e fanzineiros foram começando a reconhecer meu trabalho e estilo, que mescla a linguagem das HQs à uma poeticidade haikaizada e condensada. Cada vez mais era convidado a participar com trabalhos meus em outros zines, como "Barata", "Bifa", "Ideário", "Phobus", "Tchê" etc.

Hoje a SM Editora, cujo editor é José Salles, que tem sua sede em Jaú (SP), vem abrindo espaço para os quadrinhos poético-filo- 
sóficos. Edgar Franco já publicou dois números da revista Arlectos e Ps-Humanos por esta editora nos anos de 2006 e 2007.

Distante do grupo de autores que vem publicando os quadrinhos poético-filosóficos, mas muito próximo da proposta poética e filosófica do grupo, Marcelo Campos ${ }^{6}$ publicou no ano de 2007, pela Editora Casa 21 do Rio de Janeiro, o álbum de tiras Talvez Isso... (figura 9), que sem explicitar a intencionalidade de uma reflexão filosófica a permite abundantemente ao longo das 70 tiras nas quais colocou a criatividade e a competência técnica de um desenhista experiente. Gazy Andraus concorda que este trabalho de Campos pode ser considerado do gênero poético-filosófico (Andraus, 2008).

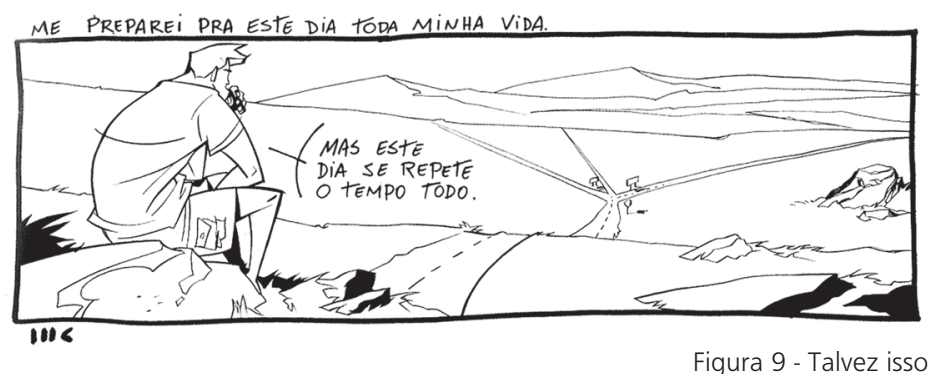

As HQs poético-filosóficas ainda são pouco conhecidas no Brasil, embora em 2007, a revista Lngua Portuguesa, de São Paulo, em trabalho assinado por seu editor Luiz Costa Pereira Junior, tenha dedicado uma extensa matéria, intitulada "Poesia em quadrinhos", ao estudo deste gênero fazendo referências ao trabalho de Henrique Magalhães como editor, e aos trabalhos dos artistas Edgar Franco, Antonio Amaral, Flávio Calazans e Gazy Andraus.

\section{As diferentes formas de expressão para definir o gênero}

Entre os artistas, estudiosos e pesquisadores do gênero poético-filosófico não há uma unanimidade quanto à expressão 
mais adequada para a caracterização do mesmo. Em fevereiro de 1995, no número 01 da revista Tyli-Tyli, seu editor, Henrique Magalhães (1995, p. 2), no editorial utiliza as expressões quadrinhos esotéricos, filosóficos ou poéticos para referir-se ao gênero que aquela revista começava a publicar:

Os quadrinhos brasileiros são ricos em seu universo criativo. Dos quadrinhos infantis, tão difundidos, ao terror, do humor debochado aos super-heróis. Desta forma, tem surgido já há alguns anos um gênero de quadrinhos que não encontra espaço para publicação que nos fanzines e revistas alternativas ou independentes: são os quadrinhos esotéricos, ou filosóficos, ou poéticos, tão bem representados pelo trabalho de Flávio Calazans, Gazy Andraus, Edgar Franco, Joacy Jamys e tantos outros. Com a revista Tyli-Tyli (dedicada à personagem homônima de Calazans) estamos criando um espaço onde todos estes novos autores poderão dar vazão a seus quadrinhos reflexivos.

No artigo da revista Mandala, no 13, de Junho de 2001, Magalhães utiliza a expressão "Quadrinhos Poéticos" para referir-se ao gênero em questão:

Os quadrinhos ditos poéticos têm como princípio a liberdade de expressão incondicional visto que fluem da subjetividade mais intrínseca do autor. Mais que qualquer outro gênero de quadrinhos, os poéticos, procuram produzir as reflexões, os questionamentos, as inquietações do artista de uma forma muito pessoal e diferenciada do senso comum. Isto é o que torna o poeta por vezes um visionário, um sujeito que enxerga outras nuanças da realidade. (2001a, p. 19).

Em entrevista a mim concedida (2007) explicou porque optou por utilizar esta expressão:

Elydio: Por que você prefere a expressão quadrinhos poéticos e não quadrinhos poético-filosóficos?

Henrique Magalhães: No início, quando ainda não tínhamos uma definição para o gênero, eu costumava chamá-los de quadrinhos poético-filosóficos, porque no geral eles tratavam de questões metafísicas, introspectivas e oníricas. Mas sempre achei o termo meio vago e muito abrangente. A filosofia requer um pensamento mais estruturado, quando a maioria dos quadrinhos 
me parecia muito subjetivos, como expressão de uma visão mais para o devaneio que para o rigor filosófico. Desse modo, dada a liberdade expressiva textual e gráfica dos autores, considerei que eles estavam mais próximos da linguagem poética que filosófica. Considerá-los apenas quadrinhos poéticos não diminui sua importância, apenas Ihes dão uma dimensão mais impressionista, mais pessoal.

Esta é também a expressão utilizada por Edgard Guimarães em seu artigo "Reflexões sobre Quadrinhos Poéticos" (2001, p. 17): Diversas considerações devem ser feitas inicialmente sobre os "quadrinhos poéticos", ou seja, sobre essa "mistura" de histórias em quadrinhos e poesia.

Henrique Torreiro, organizador da Xornadas de Banda Deseada de Ourense (Espanha) e da Expofanzines, catálogo de 1997, p. 15, utiliza a expressão "fantasia filosófica" para referir-se ao fanzine Irmos Siameses, de Edgar Franco e Gazy Andraus. Este mesmo catálogo, quando se refere ao trabalho Homo Eternus, de Gazy Andraus, adjetiva-o de cmics filosficos.

Na mesma direção de Torreiro, Gazy Andraus prefere utilizar a expressão quadrinhos fantástico-filosóficos como explicita em entrevista a mim concedida no ano de 2007:

ELYDIO: São utilizadas várias terminologias aparentemente sinônimas: quadrinhos poéticos (Henrique Magalhães), quadrinhos poético-filosóficos (Edgar Franco), quadrinhos de fantasia filosófica (Catálogo da Expo Fanzines de Ourense, Espanha). Qual você considera mais adequada ao tipo de quadrinhos que você produz? GAZY: Talvez HQs Fantástico-filosóficas, mesmo. Acho que revela a fantasia, mas ao mesmo tempo a seriedade, a busca da sabedoria, e a espiritualidade inerente. E abrange mais do que se fosse $\mathrm{HQ}$ espiritualista, só por causa dos preconceitos concernentes às questões de ordens espirituais. A abordagem do termo "filosofia" evita tal preconceito, e pode atingir mais pessoas.

As evidências das publicações mostram que foi Edgar Franco, em seu artigo no livro "As histórias em Quadrinhos no Brasil: Teoria e Prática", de 1997, organizado por Flávio Calazans, que utilizou pela primeira vez a expressão poético-filosófico ao denominar uma das linhas do que chamava de quadrinhos 
subterrâneos no Brasil como "linha poético-filosófica" (Franco, 1997, p. 54). Em correspondência eletrônica trocada comigo, quando indagado sobre a criação do termo poético-filosófico, Franco (2008) respondeu o seguinte:

Na verdade o termo quadrinhos "Poético-filosóficos" foi criado por mim para o artigo que saiu no livro "As histórias em Quadrinhos no Brasil: Teoria e Prática", de 1997 - defini a linha "poético-filosófica" lá. Detalhe importante é que o artigo foi escrito em 1995 para um número do zine DROWNED que não foi lançado. Então eu reformulei para o formato que está no livro e apresentei no Intercom de 1996 em Londrina, Calazans reuniu os artigos apresentados no GT de quadrinhos de 96 no livro que foi lançado em 1997.

Franco utiliza a mesma expressão em artigo intitulado "História em Quadrinhos Redondos", publicado na revista Mandala, número 13, de Junho de 2001, quando apresenta sua visão sobre o que sejam os quadrinhos poético-filosóficos:

A primeira maneira encontrada para tentar classificar esses trabaIhos foi chamá-los de poéticos, pois foi feito um paralelo com a literatura, ou seja, os quadrinhos tradicionais estariam para a prosa assim como os quadrinhos 'poéticos' estariam para a poesia, como todo rótulo, esse certamente foi insuficiente para classificar a abundância e diversidade dessas manifestações que não passariam despercebidas até ao mais desatento leitor que acompanhe o cenário de quadrinhos alternativos brasileiros. (...) Todos estes quadrinhistas possuem suas singularidades, mas algumas das características de seus trabalhos podem reuní-los num grupo que como disse anteriormente convencionou-se chamar de quadrinhistas poético-filosóficos, anexando a palavra filosófica ao rótulo por verificar que a maioria deles também apresentava trabalhos com a pretensão filosófica de levar o leitor a refletir sobre alguma questão existencial, citando inclusive filósofos, além de poetas. (p. 14).

Como os textos anteriores sugerem, Edgar Franco prefere a expressão quadrinhos poético-filosóficos e na mesma correspondência acima citada (2008) explica porque a considera mais adequada que os termos fantasia filosfica ou quadrinhos poticos: 


\section{Sobre "fantasia filosófica"}

É um termo que gosto muito também, mas ele é menos abrangente ao meu ver. O meu trabalho e o de Gazy se encaixam perfeitamente nessa terminologia, mas algumas HQs de Calazans, Joacy e mesmo de Amaral não podem ser consideradas HQs de "fantasia" então acredito que HQs poético-filosóficas é mais abrangente. Em uma classificação eu diria que a "fantasia filosófica" é um dos sub-gêneros das HQs "poético-filosóficas".

\section{Sobre a expressão "quadrinhos poéticos"}

É mais abrangente ainda, no entanto ampla demais. O aspecto "filosófico", questionador fica de fora, a principal característica das HQs poético-filosóficas é sua pretensão filosófica, levar o leitor a refletir sobre temas específicos, não são simples exercícios líricos de poesia quadrinhizada (é claro que existem casos assim, mas...).

E ainda, no mesmo texto (2008), explicita sua compreensão do termo poético:

\section{Sobre o termo "poética"}

Vejo a poética mais no aspecto aristotélico, de "devir" (diretamente conectada ao aspecto filosófico) - de possibilidades de vir a ser, mas no sentido de poíesis também é interessante: o ato criativo!!!! Então, para mim, a somatória de devir e criação = poética. Uso em minha tese de doutorado também o termo poética (para definir as poéticas prospectivas das ciberartes) e lá eu defendo o meu ponto de vista assim (trecho da tese página 110 - capítulo III):

Aristteles, em sua Potica, ao definir o ofcio do poeta, enfatiza o devir que envolve a atividade potica, destacando a universalidade da arte e seu valor filosfico superior ao dos relatos histricos. Sua viso da funo potica-artstica nos remete ao carter antecipatrio da FC explicado pelo deslocamento conceitual proposto por P.K. Dick e relatado no captulo II:

Não é ofício de poeta narrar o que aconteceu; é, sim, o de representar o que poderia acontecer, quer dizer, o que é possível segundo a verossimilhança e a necessidade. Com efeito, não diferem o historiador e o poeta por escreverem verso ou prosa (...) diferem, sim, em que diz um as coisas que sucederam, e o outro as que poderiam suceder. Por isso a poesia é algo mais filosófico e mais sério do que a história, pois refere aquela principalmente o universal, e esta o particular (ARISTÓTELES, 1987, p. 209). 
No contexto de minha definição das poéticas ciberartísticas prospectivas, utilizo o termo "poética" para referir-me aos métodos operacionais utilizados pelos ciberartistas, que envolvem sempre o ferramental das novas tecnologias, sobretudo: telemática, robótica, biogenética e nanoengenharia; mas também no sentido aristotélico de poética, segundo o qual a poesia é universal e envolve o devir, aquilo que pode "vir a ser".

Pessoalmente prefiro a denominação quadrinhos poético-filosóficos e considero a fundamentação de Edgar Franco, no que diz respeito à poética e à filosofia, bastante pertinente, motivo pelo qual é o termo por mim escolhido para referir-me ao gênero que aqui está sendo estudado. Cabe, no entanto, uma melhor explicitação do que entendo por filosofia ou reflexão filosófica.

Compreendo a reflexão filosófica como uma reflexão radical, rigorosa e de conjunto sobre os problemas da realidade que ameaçam nossa existência (SAVIANI, 1983), mas que não precisa, entretanto, ser construída necessariamente segundo o viés acadêmico. Há os que acreditam que somente é possível fazer filosofia na academia. Sem dúvida a academia é um espaço favorável à elaboração filosófica, mas não o único e nem necessariamente o melhor. Claro está que quem se dispõe a fazer filosofia na academia terá que estar atento aos padrões deste contexto que, em alguns casos e infelizmente, chegam a ser dificultadores para a reflexão filosófica. No entanto, é necessário lembrar que é possível construir a reflexão filosófica fora de tal contexto. De acordo com Palácios (1997, p. 33):

Há outras condições para fazermos filosofia: ter espírito crítico, imaginação e poder argumentativo. Espírito crítico para não aceitar de mãos beijadas tudo o que nos é dito ou tudo o que lemos; imaginação para estar em condições de achar soluções saídas do labirinto em que nos encontramos e poder argumentativo para fundamentar racionalmente nossas intuições. Em outras palavras, nos comportarmos na filosofia como o fazemos como seres normais: avaliar o que escutamos ou vemos ou lemos, pensar se concordamos, avaliar, refletir e decidir as coisas por nós mesmos, como pessoas adultas que não precisam ser conduzidas pelas mãos de outros adultos.

Podemos, portanto, estar em condições de filosofar mesmo antes de saber que o fazemos. 
Palácios (1997, p. 63) sugere ainda que este exercício de reflexão exige a expressão daquilo que está dentro de nós:

'Procurei a mim mesmo', diz Heráclito. Pois façamos isto. Procuremos a nós mesmos, escrevamos o que está dentro de nós, o que nós mesmos pensamos. (...) Temos as condições intelectuais para isso, não temos? Usemo-las e ousemos. Que diferente ir a um congresso de filosofia no qual só se falasse o que cada um pensa, que expusesse o fruto das próprias pesquisas, do próprio trabalho, sem comentários, sem enésimas leituras; um congresso em que cada um tivesse a coragem de se expor e de dizer quem está certo e quem está errado e porque; dizer, também, porque o próprio expositor está certo.

Assim o exercício da reflexão filosófica, exercido com radicalidade, dentro ou fora da academia, pode contribuir com a formação de seres humanos com capacidade de autonomia e de autoria. Se pensarmos que estamos num país que precisa que seus cidadãos se assumam como autores de sua própria história, então teremos clareza da urgência da tarefa filosófica, como na perspectiva aqui sugerida.

Penso que as histórias em quadrinhos poético-filosóficas podem provocar este tipo mais aberto de reflexão filosófica e desta forma contribuir com o processo de constituição do modo de ser humano e brasileiro diante das exigências problemáticas do mundo contemporâneo.

\section{O que são histórias em quadrinhos poético- filosóficas?}

A seguir apresento uma tentativa de definição de alguns aspectos que definam as histórias em quadrinhos poético-filosóficas considerando, de modo especial, as visões de alguns artistas, estudiosos e pesquisadores das mesmas. É importante frisar que o empenho por definir apropriadamente o gênero manifestou-se, pela primeira vez, nas páginas da revista Mandala em pequenos estudos coordenados por Henrique MagaIhães a partir de uma correspondência enviada por João Antô- 
nio Buhrer D'Almeida, em 04 de junho de 1998, conforme relata o próprio editor (Magalhães, 2000), e na qual João Antônio falava da necessidade de uma discussão mais ampla sobre o tema. A seguir recolho, entre outros, algumas das contribuições que foram publicadas nas páginas daquela revista.

\subsection{O que dizem artistas, estudiosos e pesquisadores?}

Edgar Franco, artista e pesquisador, assim define o que chamou, em 1997, de linha poético-filosófica dos quadrinhos subterrâneos no Brasil:

Quadrinhistas que passam mensagens filosóficas e questionamentos existenciais em seus trabalhos, muitas vezes lançam mão de textos poéticos de sua autoria ou de outrem como roteiro para suas HQs. Nem sempre têm compromisso com a linearidade da narrativa, além disso, são caracterizados por muito experimentalismo no enquadramento e no traço. (1997, p. 54)

Para Franco, portanto, dois aspectos basicamente definem as histórias em quadrinhos poético-filosóficas: 1. O fato de apresentarem uma intencionalidade filosófica ou reflexiva e também poética; 2 . O trabalho diferenciado com a linguagem quadrinhística, expresso na quebra da linearidade narrativa e no experimentalismo do traço e do enquadramento.

Gazy Andraus, igualmente artista e pesquisador, em seu artigo "HQs fantástico-filosóficas: gênero único no Brasil", também identifica as duas características explicitadas por Edgar Franco e acrescenta uma terceira. Para ele (2008a, p.6 - 7) as histórias em quadrinhos poético-filosóficas tendem a ser curtas, isto é, apresentam poucas páginas e, às vezes, uma única página, o que pede uma leitura diferenciada do apreciador, ou seja, uma leitura e uma interpretação menos convencional, menos cartesiana:

O que os autores de HQs poéticas, ou então, fantástico-filosóficas fazem, é ir direto à essência de tais buscas humanas, "filtrando-as", ou canalizando-as diretamente em uma arte "condensada", sintetizada, similar à forma dos hai-kais, que torna muitas vezes 
difícil o entendimento racionalizado instantâneo do leitor.

Um Hai-Kai tem uma estrutura própria, em que a poesia, métrica, rítmica a torna direta, sem que aparente o ser: faz com que a mente do leitor se torne focada, pense mais rapidamente, e conclua de uma forma muitas vezes "inconclusa". (...) Reafirmo, porém, exclusivamente, que a dita "Fantasia-filosófica" tem as características de um koan e/ou hai-kai: uma história de poucas páginas, de mensagem condensada, em que aparentemente não há uma narrativa que contemple começo, meio e fim tradicionais, em que não aconteçam situações dramáticas comuns e sim, mensagens oriundas de um autor cujo pensar se torna "condensado" e atinge da mesma forma o leitor.

Geralmente são HQs que precisam de uma preparação melhor dos leitores, pois que estão acostumados com as narrativas tradicionais com muitos quadrinhos e páginas, que têm uma linearidade mais clara e abrangente...o cérebro em sua atividade racional se compraz em tais narrativas já que acostumamo-nos a usar cotidianamente o processamento da razão muito mais do que o da intuição criativa. E sente dificuldade em "entender" outros tipos de narrativas, de "lógicas".

Em entrevista a mim concedida Gazy Andraus (2007) não nega, mas relativiza a influência de autores europeus - autores de HQs fantásticas como Caza, Moebius e Druillet - no processo de criação das HQs poético-filosóficas brasileiras, e aponta o caráter "condensado" dos quadrinhos brasileiros como uma diferença muito importante em relação aos quadrinhos europeus:

Elydio: Você concorda com a afirmação de que as HQss poético-filosóficas brasileiras sofreram forte influência da fantasia poética européia, de modo especial por meio dos trabalhos de Caza, Druillet e Moebius?

Gazy: Sim, mas não consciente, e nem total. Já fazíamos assim aqui. Uma de minhas primeiras HQs foi "Vil Existência", que trazia um estilo artístico similar aos das HQs com um viés narrativo europeu. Isso sem que eu conhecesse o quadrinho europeu direito. (...) Porém, há uma diferença básica das HQs de lá e as daqui: aqui fazemos HQs curtas, "nervosas" e mais condensadas, e lá, não. Aqui, isso acontece, acredito eu, devido às idiossincrasias de nosso povo, afeito à influência mais direta e espiritual do que noutros lugares. (...) Mas acho que aqui elas são mais incisivas e mais diretas ao hemisfério direito do cérebro, do que as de lá. Na França, as HQs 
non-sense de Moebius têm essa conotação, e algumas antigas de Caza também. Atualmente, não sei dizer, mas parece que se renderam todos ao mercado, fazendo HQs longas, de epopéias, como os norte-americanos. A obra de Caza se diluiu e perdeu muito a força atualmente. Eu vejo as HQs fantástico-filosóficas (assim alcunhadas por Henrique Torreiro) como a contra-parte dos haikais, na forma de HQs: mensagens condensadas, visuais-literárias, para quebrar a mente racional, tal como os koans zen-budistas são utilizados pelos mestres para trazerem a mente cósmica a seus discípulos.

Henrique Magalhães - pesquisador, editor e desenhista - assim expressa sua maneira de compreender as HQs poético-filosóficas, apontando também para as características da reflexão e do rompimento com a formalidade dos quadrinhos comerciais como importantes para a identificação do gênero:

Quando comecei a observar mais atentamente os quadrinhos poéticos vi-os pelo prisma da contestação política, por meio do trabalho de tendência anarquista de Flávio Calazans. Gazy Andraus e Edgar Franco já me tinham chamado a atenção pela forte expressão visual inconfundível e incomparável nas HQs brasileiras. Além dos três autores chaves citados, acrescentaria Wally Viana e Henry e Maria Jaepelt (...). O ponto comum desses autores é a produção de quadrinhos de caráter muito pessoal, que poderemos considerar como sendo poéticos e filosóficos, pois aludem às questões mais interiorizadas de cada um. Outro elemento marcante é o rompimento com a formalidade dos quadrinhos comerciais, com a freqüente eliminação do quadro como limite espacial e pelo fluxo atípico de narrativa. Como exemplo, cito os quadrinhos de Calazans que inúmeras vezes formam páginas sem hierarquização do texto, podendo ser lidas sob os mais diversos ângulos. (...) É certo que os quadrinhos podem prescindir do texto, mas não o contrário: não se concebe uma história em quadrinhos sem imagens. Portanto, o texto deve estar vinculado à imagem, complementando-a ou reforçando-a, sem descrevê-la literalmente. (...) Nesta categoria encaixo as histórias em quadrinhos 'poéticas'. O texto divide com a imagem a função da comunicação, tornando-se inseparáveis e complementares. Como ocorre, aliás, com as melhores histórias em quadrinhos, de qualquer gênero. Não resta dúvida, portanto, que os 'poemas ilustrados' são histórias em quadrinhos e formam um gênero à parte, os "Quadrinhos Poéticos". Nele, o autor trabalha sua subjetividade, aguçando a percepção do leitor e propondo novas formas de leitura. Uma leitura centrada na imagem que eventualmente é complementada pelo texto, que por sua vez apresenta-se repleto 
de subjetividade (2000, p. 17-18).

Para Edgard Guimarães (2001, p. 18) a principal característica das HQs poético-filosóficas parece estar principalmente na temática poética e reflexiva:

O ponto principal, no entanto, sobre os quadrinhos poéticos diz respeito ao conceito mais amplo do que seja poesia. (...) Poesia é a expressão que toca "a alma" do ser humano, mesmo que não se possa definir com precisão o que seja "tocar a alma". Assim o poeta pode se expressar usando a palavra escrita, tanto em versos como em prosa, ou usando imagens como o desenho e a fotografia, e obviamente a história em quadrinhos não ficaria de fora como forma de expressão poética. (...) Os quadrinhos poéticos incluem, portanto os trabalhos que aparentam ser HQss normais, mas cujos temas ou desenvolvimentos "toquem a alma", como Gaiman em "Sandman", Hugo Pratt em "A Balada do Mar Salgado" ou Jim Starlin em "A morte do Capitão Marvel" .

Também eu, em trabalho anterior, localizei na reflexão filosófica uma das principais características do gênero poético-filosófico:

É importante, pois, deixar claro que as HQs poético-filosóficas têm como uma de suas marcas principais provocar a reflexão filosófica, não no sentido de gerar, necessariamente, textos rigorosos como na academia, mas no sentido de convocar uma reflexão mais aprofundada, na perspectiva das subjetividades de seus autores, sobre alguns aspectos da condição humana (SANTOS NETO, 2007, p. 4).

\subsection{Definição e caracterização das histórias em quadrinhos poético-filosóficas: um esforço de síntese}

A partir do quanto foi trazido aqui, como contribuição dos vários artistas e estudiosos do tema, é possível afirmar que histórias em quadrinhos poético-filosóficas são aquelas que apresentam, de maneira explícita em sua arte, a intenção de que seja feita uma reflexão poética, enquanto aberta criativamente ao contínuo movimento da vida, e filosófica, enquanto provocação a um pensar aprofundado sobre a condição humana. As 
histórias em quadrinhos poético-filosóficas tendem a ser apresentadas em histórias curtas que, muitas vezes, rompem com a linearidade convencional das narrativas em quadrinhos usando, para tanto, de criativos recursos seja no traço do artista seja em novas propostas de utilização dos requadros.

São, portanto, três as características que principalmente definem uma história em quadrinhos poético-filosófica: 1. A intencionalidade poética e filosófica; 2 . Histórias curtas que exigem uma leitura diferente da convencional; 3. Inovação na linguagem quadrinhística em relação aos padrões de narrativas tradicionais nas histórias em quadrinhos.

Quando se fala da intencionalidade poética aqui é no sentido sugerido por Edgar Franco, que se referenciou no pensamento de Aristóteles, isto é, um olhar que, sem perder completamente o pé do chão presente e estando aberto aos influxos criativos da imaginação, consegue vislumbrar as coisas que ainda não são e trazê-las para a fruição e reflexão do leitor ou leitora. Da mesma forma, quando se fala na intencionalidade filosófica não se está pensando aqui na filosofia que está presente necessariamente em qualquer obra de arte, mesmo naquela que se destina a fazer rir ou a ajudar a passar o tempo. Nem se está pensando naqueles autores que, como Alan Moore $^{8}$, por exemplo, conseguem construir reflexões filosóficas em quadrinhos já consolidados no mercado formal. E muito menos se está pensando naqueles trabalhos que usam a linguagem das histórias em quadrinhos para introduzir ao pensamento de filósofos já consagrados, seja do pensamento ocidental ou oriental. Quando se fala de intencionalidade filosófica a referência é ao desejo, que explicitam os autores poético-filosóficos, de provocar uma reflexão mais profunda sobre a condição humana em seus leitores e leitoras e, para isso, compartilham suas visões sociais, oníricas, subjetivas, cósmicas, políticas e espirituais por meio da linguagem dos quadrinhos.

A inovação da linguagem, as histórias curtas e condensadas e, com certeza, o apelo à reflexão pedem um leitor diferenciado em relação aos padrões habituais. A construção do sentido da história e sua interpretação passam, em grande 
parte, pela experiência que o mesmo fez com a leitura. O sentido não é imediatamente dado e nem é fruto de uma lógica detetivesca, mas depende muito mais dos estados de consciência percebidos e refletidos pelo leitor ao longo da narrativa imagética. E, sob um certo ângulo, portanto, é possível falar numa co-autoria do leitor naquilo que diz respeito à construção de sentido, isto é, os quadrinhos poético-filosóficos, em certa medida, contribuem para o processo de construção de autoria, de autoconhecimento e de autonomia daqueles que os lêem. Isto é tarefa bastante exigente para um leitor e os leitores do gênero poético-filosófico, certamente, ainda existem em número restrito se comparados com a grande maioria dos leitores brasileiros.

\section{Histórias em quadrinhos poético-filosóficas: 0 diálogo arte-comunicação-educação para ajudar a pensar a condição humana}

As duas últimas décadas do século $X X$ trouxeram mudanças significativas tanto no cenário internacional como nacional. Vimos o avanço radical do neoliberalismo e da globalização econômica; a crise e o desmoronamento do socialismo real expresso, de modo simbólico, na queda do muro de Berlim; a crise dos paradigmas tradicionais para a produção de conhecimento e a emergência de um discurso, de caráter pós-moderno, que afirma a impotência da condição humana para a construção de utopias de igualdade e transformação da sociedade; os estupendos avanços da tecnologia favorecendo, por um lado, o aumento de benefícios em termos de saúde, educação e comunicação, mas, por outro, permitindo a sofisticação do consumo e o conseqüente aumento da exclusão e do fosso entre ricos e pobres; a emergência econômica de países do oriente; os conflitos bélicos entre nações do ocidente e do oriente com conseqüências e implicações imediatas para os demais países do planeta, principalmente aqueles com condições econômicas mais consolidadas; e, ainda, a agonia do planeta, 
de modo especial em seus aspectos ambientais, sob o forte caráter predatório das relações exploratórias estabelecidas pelos seres humanos.

Este contexto nos faz perguntar: Que mundo estamos construindo? Para onde estamos caminhando? A história acabou mesmo? Não há saídas? Não será possível justiça e solidariedade sobre o planeta Terra? E nós brasileiros estamos fadados a simplesmente repetir o sucesso e a imposição de outras culturas? Temos uma contribuição a dar neste momento de construção/desconstrução da civilização planetária? É neste quadro de perguntas e dúvidas que compreendo a importância dos quadrinhos poético-filosóficos. Eles são uma criação cultural que dialoga com as questões existenciais do homem contemporâneo com um grande repertório de temas - existenciais, espirituais e filosóficos - como: o sofrimento humano, a morte, a esperança, o destino, o ego encapsulado em si mesmo, a mente humana, o feminino materno, a consciência planetária, a consciência cósmica, o imediatismo e o consumismo, a ciência, a religião, as instituições sociais, o autoconhecimento, a tensão entre as polaridades masculina e feminina do ser, a sexualidade, o poder, as lutas e contradições internas do ser humano, a fraternidade, a fratricidade, a evolução dos homens e dos animais, a espiritualidade, o inacabamento humano e a construção da liberdade.

Vejo, assim, que as histórias em quadrinhos poético-filosóficas poderão auxiliar a compreender como a educação, a arte e a comunicação estão imbricadas na cultura contemporânea e quais problemas e possibilidades de respostas criativas estão presentes neste universo no atual momento histórico de nossa cultura. É importante que tais artistas continuem, portanto a produzir e a dialogar com o nosso tempo.

\section{Finalizando...}

A HQ "Parto", de Edgar Franco, que consta na íntegra no ensaio visual desta revista, e que pedi ao leitor ou leitora que examinasse antes de iniciar a leitura deste trabalho, é um bom 
exemplo de uma história em quadrinhos poético-filosófica. É uma história de apenas cinco páginas em que não há os requadros tradicionais das HQs. Cada página, por assim dizer, confunde-se com um grande quadrinho. O traço estilizado e sofisticado de Edgar Franco destaca-se e o leitor atento poderá observar detalhes simbólicos preciosos na construção de cada imagem. Nelas sente-se a tensão entre os humanos que éramos/somos e os humanos (pós-humanos?) que podemos vir a ser.

A HQ começa com uma referência aos úteros artificiais entendidos como eletrodomésticos acessíveis. Eles substituem a antiquada reprodução sexuada: sofrida, desgastante, perigosa, mas também prazerosa. Certamente está presente aqui o tema da tecnologia no processo humano de desenvolvimento. Qual o lugar da tecnologia no projeto ético que nós humanos queremos desenvolver?

A narrativa assume, pois, como problema central de sua reflexão, o projeto ético que estamos construindo como humanidade, de modo especial com a presença das tecnologias avançadas. "Poucos insistem na ancestral técnica biológica, que desgasta o corpo e está sujeita a erros do acaso..." diz o texto da HQ. Será possível termos o controle absoluto de tudo? Será sadio termos o controle de tudo? O que nos assusta em não termos o controle sobre todas as coisas? São as imperfeições? As deficiências? O que são as imperfeições e as deficiências na ordem das coisas? Haverá perfectibilidade nas imperfeições e nos erros? Primeiro Otto Rank e depois Stanislav Grof nos ensinaram que o trauma do parto tem sido um momento importante para constituição do ser humano. Nele aprendemos o processo doloroso de morte e renascimento. A vida é um permanente movimento que supõe saber morrer para o que já passou e saber nascer para o novo que está nascendo ou renascendo. Este aprendizado, contudo, é feito na dor. Será possível abolir este processo? Será possível eliminar a dor? Será desejável? Qual o limite aceitável da dor? Eliminar a dor seria eliminar nosso aprendizado para enfrentar a construção da existência?

A HQ provoca a pensar que tipo de seres "humanos" estamos ajudando a se constituir com as nossas tecnologias. No 
mundo futuro talvez não seja mais característica dos partos o choro das crianças, que morreram para a vida do útero e nasceram para a vida nas culturas e sociedades humanas. Talvez elas nasçam sorrindo uma vez chegadas à maturação. Talvez não corram mais os riscos de um "berço ruim" como no útero antigo. Mas haverá para elas a possibilidade de conhecer a alegria e a serenidade da vitória de quem trilhou o caminho entre a morte e o renascimento? Ou haverá "uma profunda tristeza enigmática em seus semblantes"? O que queremos? O que estamos fazendo?

Com certeza trabalhos deste tipo, se utilizados, por exemplo, como provocações em trabalhos educativos, na educação formal e não-formal, poderão auxiliar o estabelecimento de diálogos e experiências que favoreçam o trato compreensivo com os desafios da condição humana (e pós-humana?). Isto é bastante desejável, mas será possível?

Tive a oportunidade de perguntar a Henrique Magalhães (2007), um dos primeiros editores a abrir-se com entusiasmo ao gênero poético-filosófico, o que ele pensava sobre o futuro deste gênero em terras brasileiras e ele me respondeu o seguinte:

No Brasil não há a menor chance de uma cultura como essa vingar nos meios comerciais. O que resta é o entusiasmo dos autores com suas auto-edições. Isto não é pouco, mas não garante a profissionalização. De todo modo, acredito que os quadrinhos poéticos são uma das expressões mais fortes do que se pode chamar de quadrinho autoral e não devem ser abandonados de vez.

De minha parte vejo, claramente, as dificuldades que aponta Henrique Magalhães e comungo com ele da vontade de ver o gênero prosseguir, pois fico fortemente tocado pelo seu potencial reflexivo, transformador, político, estético, educativo e desejo que os artistas continuem a produzir sua obra, ainda que seja numa cultura cujo mercado oferece muitos obstáculos para acolhê-la e divulgá-la. Que consigam manter vivo o entusiasmo pelas HQ poético-filosóficas, pois está aí um trabalho capaz de provocar transformações na direção de uma cultura com mais alegria, beleza e, por que não, na direção da "criação 


\section{de um mundo em que seja menos difícil amar" (PAULO FREIRE, 1982, p. 218).}

\section{Notas}

1. Conferir o relato em: http://www.ibacbr.com.br/ ?dir=artigos\&pag=013\&opc=0086. Acesso em 14 de setembro de 2008.

2. O nome da revista é uma homenagem a uma das principais personagens de Flávio Calazans.

3. Foi o editor que lançou, no Brasil, as primeiras revistas dedicadas exclusivamente aos quadrinhos poético-filosóficos. Natural de João Pessoa, Paraíba, onde criou, em 1975, a personagem de HQs "Maria", publicada em tiras diárias em diversos veículos no Brasil e em Portugal. Fez Mestrado na Escola de Comunicação e Artes da Universidade de São Paulo e Doutorado na Universidade de Paris VII, ambos com estudos dirigidos aos fanzines de histórias em quadrinhos. Atualmente é professor do Curso de Comunicação Social na UFPB. Dirige a editora Marca de Fantasia (nome que tem origem no fanzine homônimo e que foi criado por Magalhães; www.marcadefantasia.com.br), lançando o fanzine Top! Top!, as revistas Mandala, Quiosque, Maria Magazine e a coleção Corisco, além de álbuns e livros sobre quadrinhos e cultura alternativa.

4. Quadrinhista e Editor Independente. Mestre em Ciências pelo Instituto Tecnológico de Aeronáutica. Participou do livro "História em Quadrinhos - Teoria e Prática" organizado por Flávio Calazans. Publicou os livros "Fanzine", um estudo sobre publicações independentes, "Algumas Leituras sobre Príncipe Valente" e organizou a publicação do livro "O que é Histórias em Quadrinhos Brasileira", todos pela Editora Marca de Fantasia.

5. Conferir o relato em: http://www.ibacbr.com.br/?dir=artigos\&pag=013\&opc=0082. Acesso em 14 de setembro de 2008.

6. Marcelo Campos é desenhista de quadrinhos e diretor da Quanta Academia de Artes. Trabalhou em diferentes campos das artes visuais e ficou conhecido por ter sido o primeiro brasileiro da nova geração a publicar seus trabalhos nos Estados Unidos. Hoje divide seu tempo entre dirigir sua escola de artes e partilhar, pela docência, a grande experiência que tem com as histórias em quadrinhos.

7. Neste artigo estou preocupado em identificar e explicitar os traços do que sejam as histórias em quadrinhos poético-filosóficas no Brasil. Por certo é possível, guardadas as devidas distâncias, encontrar trabalhos próximos em outros países e culturas, como sugerem Edgard Guimarães e também algumas produções européias, mas não é meu objetivo, neste momento, realizar este estudo e nem mesmo fazer uma aproximação crítico-comparativa.

8. Roteirista de origem inglesa que ficou conhecido por escrever textos para as histórias em quadrinhos de forma criativa e usando largamente motivos e referências filosóficas e literárias. Também escreveu histórias de super-heróis, como Super-Homem e Batman, que se tornaram muito conhecidas. Alguns de seus trabalhos significativos são: "Do Inferno",

"Wathcmen" e "V de Vingança". 


\section{Referências bibliográficas}

ANDRAUS, G. Homo Eternus (1 de 4). São Vicente: Fanzine/Edição do Autor, 1993 a. . Homo Eternus (2 de 4). São Vicente: Fanzine/Edição do Autor, 1993 b. . Homo Eternus (3 de 4). São Vicente: Fanzine/Edição do Autor, 1993 c. Homo Eternus (4 de 4). São Vicente: Fanzine/Edição do Autor, 1993 d. - Terra e Plantio. In: Revista Brasilian Heavy Metal. São Paulo: Comix, 1996, p. 67-70. .Ternrio M. E. N. João Pessoa: Marca de Fantasia, 2001, p. 7-8.

. Existe o quadrinho no vazio entre dois quadrinhos? (ou: o Koan nas Histrias em Quadrinhos Autorais Adultas). São Paulo: Universidade Estadual Paulista (Instituto de Artes Visuais - UNESP), 1999. (Dissertação de Mestrado) As Histrias em quadrinhos como informao imagtica integrada ao ensino universitrio. São Paulo: Universidade de São Paulo (Escola de Comunicações e Artes), 2006 a. (Tese de Doutorado)

.História em Quadrinhos, Imagética e Infância. In: http://www.ibacbr.com.br/artigos.php?dir=artigos\&op $c=013 \&$ idartigo $=0013$. Último acesso em 19 de novembro de 2006 (2006b).

. Entrevista concedida a Werner José Lisbôa Krapf. In: Anexo de E-mail de Gazy Andraus para Elydio dos Santos Neto, em 10 de maio de 2007, às 03:54, 2007 a.

Entrevista concedida a Elydio dos Santos Neto. In: Anexo de E-mail de Gazy Andraus para Elydio dos Santos Neto, em 21 de maio de 2007, às 06:02, 2007b. 
HQs fantástico-filosóficas: gênero único no Brasil. Jornal Graphiq, no 14, janeiro, 2008a.

. HQs fantástico-filosóficas: gênero único no Brasil. Dois estudos de caso. Jornal Graphiq, no 15, fevereiro, 2008b.

. História em quadrinhos, imagética e início da maturidade - XV: Da semelhança à criatividade. In: http:// $w w w$. ibacbr.com.br/?dir=artigos\&pag=013\&opc=0082. Último acesso em 22 de setembro de 2008 (2008c).

AMARAL, A. Hipocampo: 3a ocorrência. Terezina/São Paulo: Pulsar/Opera Graphica, s/d.

CALAZANS, F. A arte das Histórias em Quadrinhos de Gazy Andraus. In: ANDRAUS, G. Homo Eternus (1 de 4). São Vicente: Fanzine/Edição do Autor, 1993, p.3.

de Fantasia, 2001.

. Guerra das Idias. 4ed. João Pessoa: Marca

- Guerra dos Golfinhos. João Pessoa: Marca de Fantasia, 2002.

lo: Paulus, 2004.

Histria em quadrinhos na escola. São Pau-

CAMPOS, M. Talvez isso... Rio de Janeiro: Casa 21, 2007.

FRANCO, E. S. Panorama dos Quadrinhos subterrâneos no Brasil. In. CALAZANS, F. M. A. (Org.) As histrias em Quadrinhos no Brasil: Teoria e Prtica. São Paulo: Intercom/Unesp/Proex, 1997, p. 51-65.

Histórias em quadrinhos redondos. In: Revista Mandala, no 13, Junho de 2001, João Pessoa: Marca de Fantasia, p. 14-16.

tasia, 2002.

Agartha. 2ed. João Pessoa: Marca de Fan-

. Transessncia: transcendendo a essncia. João Pessoa: Marca de Fantasia, 2003.

HQtrnicas: do suporte papel rede internet. São Paulo: Annablume:Fapesp, 2004. 2005.

Elegia. João Pessoa: Marca de Fantasia, Perspectivas ps-humanas nas ciberartes. São Paulo: USP/ECA, 2006. (Tese de Doutorado). 
Arlectos e ps-humanos, no 1, 2006, Jaú/SP:

SM Editora.

Arlectos e ps-humanos, № 2, 2007, Jaú/SP:

SM Editora.

Respondendo: Quadrinhos potico-filosficos!. In: E-mail de Edgar Franco para Elydio dos Santos Neto, em 14 de setembro de 2008, às 12h35, (2008).

FRANCO, E. \& COUTO, M. BioCyberDrama. São Paulo: Opera Graphica Editora, 2003.

FREIRE, P. Pedagogia do Oprimido. 11ed. Rio de Janeiro: Paz e Terra, 1982.

GROENSTEEN, T. Histrias em Quadrinhos: essa desconhecida arte popular. João Pessoa: Marca de Fantasia, 2004.

GROF, S. Alm do Crebro: Nascimento, Morte e Transcendncia em Psicoterapia. São Paulo: McGraw-Hill, 1987.

GUIMARÃES, E. Reflexões sobre quadrinhos poéticos. In: Revista Mandala, no 13, junho de 2001, João Pessoa: Marca de Fantasia, p. 17-18.

MAGALHÃES, H. Editorial. In: Revista Tyli-Tyli, fevereiro de 1995, João Pessoa: Marca de Fantasia, p. 2.

. Poesia e Quadrinhos, In: Revista Mandala, n. 12, junho de 2000, João Pessoa: Marca de Fantasia, p. 17-18.

Quadrinhos Poéticos: viagem obtusa aos meandros da alma, In: Revista Mandala, n. 13, junho de 2001a, João Pessoa: Marca de Fantasia, p. 19-20.

.Transcendência e poética visual. In: ANDRAUS, G. Ternrio M. E. N. João Pessoa: Marca de Fantasia, 2001 b, p. 7-8.

Marca de Fantasia, 2004.

A nova onda dos fanzines. João Pessoa:

Entrevista concedida a Elydio dos Santos Neto. In: Anexo de E-mail de Henrique Magalhães para Elydio dos Santos Neto, em 22 de maio de 2007, às 00:48, 2007.

PALACIOS, G. A. De como fazer filosofia sem ser grego, estar morto ou ser gnio. Goiânia: Editora da UFG, 1997.

PEREIRA Jr., L. C. Poesia em quadrinhos. In: Revista Lngua Portuguesa, ano II, n. 18, abril de 2007, São Paulo: Editora 
Segmento, p. 22-27.

SANTOS NETO, E. Os quadrinhos poético-filosóficos de Gazy Andraus: provocações de uma visão crítica, espiritual e afirmativa da vida. In: Anais do XXX Congresso Brasileiro de Cincias da Comunicao, Santos, 29 de agosto a 02 de setembro de 2007.

- Transgressão, Transcendência e Esperança: os quadrinhos poético-filosóficos de Edgar Franco. In: Anais do XXXI Congresso Brasileiro de Cincias da Comunicao, Natal, 02 a 06 de setembro de 2008.

SAVIANI, D. Educao: do senso-comum conscincia filosfica. 3ed. São Paulo: Cortez/Editora Autores Associados, 1983.

SRBEK; CYPRIANO; MUNIZ e IRRTHUM. Quantum. Belo Horizonte: Prefeitura de BH, 2001.

\section{Elydio dos Santos Neto}

Doutor em Educação pela PUC-SP. Docente-pesquisador do Mestrado em Educação da Universidade Metodista de São Paulo (UMESP), membro do Observatório de Quadrinhos da USP, do Grupo INTERESPE e do Grupo de Estudos e Pesquisa Paulo Freire da UMESP. Pós-doutorando no Instituto de Artes da UNESP com a pesquisa "As Histórias em Quadrinhos poético-filosóficas no Brasil: Contextualização histórica e estudo das interfaces educação, arte e comunicação". 